\title{
Sensory Characteristics in ASD
}

\author{
Mary E. Stewart*, Natalie Russo, Jennifer Banks, Louisa Miller \\ and Jacob A. Burack
}

\begin{abstract}
In this paper, we review evidence regarding differences in the types of sensory experiences of persons with ASD with respect to both unisensory and multisensory processing. We discuss selfreports, carer questionnaires as well as perceptual processing differences found in the laboratory. Incoming information is processed through one or more of our senses and fundamental differences in the processing of information from any sensory modality or combination of sensory modalities are likely to have cascading effects on the way individuals with ASD experience the world around them, effects that can have both positive and negative impact on a individual with ASD's quality of life.
\end{abstract}

\section{INTRODUCTION}

The initial anecdotal, carer report and empirical evidence about sensory processing among persons with ASD seems to suggest a unique profile with examples of both hyper- and hypo-sensitivity and fluctuations between the two $(1,2)$. These extremes are reported, with varying degrees of scientific authority for all the senses - visual, auditory, taste, olfaction and touch. For example, in a self-report of sensory sensitivity, Stephen Shore (2001) writes (3):

"I have strong sensitivities to sounds. When I was in grade school, my classmates used to call my name as softly as they could to see if I could still hear them - I could hear them from across the room and often even into an adjacent classroom."

This auditory sensitivity is not restricted to names, as Shore suggests that children with ASD may hear a plane or a train much before others can hear it, and that other senses, such as smell and touch, are also especially sensitive. He provided an example of his own ability to

\footnotetext{
*To whom correspondence should be addressed: Dr Mary Stewart Applied Psychology School of Life Sciences Heriot-Watt University Edinburgh EH14 4AS United Kingdom m.e.stewart@hw.ac.uk
}

detect perfume on a lady from the floor below. Similarly, Attwood (1998) notes that persons with ASD may be distracted by a small, apparently meaningless noise to the extent that it interferes with other activities (4). However, this enhanced perception can also have beneficial outcomes as:

“.. determining variations in two or more
examples of text or graphical formatting,
music and other objects is easy and
enjoyable." (3)

In an attempt to provide insight about the sensory experiences of individuals with high functioning autism, Jones et al. (2003) summarize first-hand web page accounts of unusual sensory experiences into 4 core categories of sensory perceptual experiences that they term as turbulent sensory experiences, coping mechanisms, enjoyable sensory experiences, and awareness of being different (5). Turbulent sensory experiences refer to hypersensitive senses involving all modalities that can reach a level at which the individual feels overwhelmed to the extent of sensory overload. Coping mechanisms include behaviours implemented intentionally to help deal with an unpleasant sensory experience, examples of coping mechanisms might be engaging in other sensory experiences; avoiding distressing stimuli; partaking in repetitive behaviours; or becoming 'absorbed' in one aspect of the environment. Enjoyable sensory experiences occur when individuals are able to control their sensitivities, 
and experience sensory stimulation for fun. For example, a woman named "Jane" notes that:

"All things are heightened for me, so what a
regular person would be tickled with
pleasure over, I'll be totally ecstatic. There
are other personal rituals I do simply for
sensory pleasure. They include rhythmic
movements and sounds I make to myself. It
fills my being with a sensual phenomenon,
both serene and stimulating."

All of the individuals reported a sense of being different, in that they were aware that sensory processing of their peers was not as sensitive as their own, and that others saw and heard things in a different way than they did.

The differences in the sensory experience are not limited to stimuli in single modality. Sensory integration is also reported to be altered in ASD. Persons with ASD note a difficulty with sensory combinations. Personal vignettes include examples of difficulty in the reception and processing of information from vision, sound, taste, and smell, and difficulties processing information from more than one modality concurrently (e.g. (6-8)). For example, Toto Rajarshi Mukhopadhyay, a 14-year-old boy with ASD writes in his book, The Mind Tree, that (9):

"I have a definite problem. When I am concentrated on the sound, I felt my eyes and nose shutting off. I could never do everything together at the same time. That is, I could not see you and at the same time hear you. The result was knowledge of a fragmented world perceived through isolated sense organs."

These examples of self-report provide some insight into the sensory experiences of people with ASD.

\section{QUESTIONNAIRE STUDIES}

Carer questionnaires are a more systematic approach to studying sensory characteristics. This method has been useful in documenting greater sensory sensitivities for persons with ASD in relation to typically developing persons and persons with developmental delays. A higher level of sensory characteristics are reported for all sensory modalities in questionnaire studies (10-14). For example, on the short-form of the Sensory Profile it was found that parents of children with ASD between the ages of 3 and 13 years reported $85 \%$ more hypo- or hyper- sensory sensitivities than were reported for a group of typically developing children of the same age $(12,15)$. Although a comparison to children matched on mental-age, or developmental level might have yielded different results, these findings suggest that the sensory experience of persons with ASD differs from that of typically developing persons. Other researchers have extended these findings to show that sensory sensitivities among persons with ASD are also quantitatively and qualitatively different in relation to children with general developmental delay (13).

Baranek et al. (2006) used the Sensory Experiences Questionnaire (SEQ) which is a caregiver report questionnaire specifically designed to evaluate behavioural responses to common everyday sensory experiences among children aged between 5 months to 6 years (16). The items reflect either hyper or hyporesponsive pattern of sensory activation, and are relevant to both the social and non-social nature of the sensory experience. Baranek et al. found that carers reported a higher level of hypo-responsiveness in both social and non-social contexts among children with ASD compared to those with developmental disability and typically developing individuals (16). Hyperresponsiveness was reported by carers to be similar in the ASD and developmentally delayed groups, but higher than in the typically developing group. Thus, atypical sensory characteristics are not unique to ASD $(17,18)$, but the higher rates that are commonly reported by carers of children with ASD as compared those of typically developing children (e.g.(19)) and even of other developmentally delayed groups (e.g. (16)) can clearly affect the relationship with the environment. Although carer questionnaires are generally systematic and pragmatic, the data still needs to evaluated with caution as the responses are based on the carer's, rather than the child's, interpretations and views of the behaviours.

Leekam et al. (2007) extended this work with the use of the the Diagnostic Interview for Social and Communication Disorders (DISCO) (20-22), an interview based clinical measure administered by trained interviewer to carers. The DISCO includes 21 items that relate to proximal (e.g. touch, taste, smell, kinaesthetic), auditory, or visual sensory characteristics. The DISCO also includes items relating to atypical taste/oral, kinaesthetic, and touch responsiveness. Using this measure Leekam et al. reported that over $90 \%$ of children and adults with ASD experienced sensory abnormalities in multiple sensory domains and that sensory abnormalities are pervasive, multimodal and persistent.

\section{LABORATORY BASED STUDIES}

The anecdotal and carer reports of sensitivity to stimuli and enhanced perception of sensory stimuli among persons with ASD appears to be consistent with the 
notion of enhanced perceptual processes that are identified in experimental studies $(23,24)$. For example, in the visual domain, children with ASD are quicker than mental age matched typically developed children, and mental and chronological age matched children with intellectual disability on a task called the embedded figures test in which a design that is 'hidden' in a larger picture must be identified (25). The performance of typically developing persons appears to be interfered with by the 'visual gestalt' of the picture, whereas the performance of persons with ASD appears to be facilitated by enhanced local processing. Within the visual domain, the priority of local processing is also evident in discrimination tasks, in which persons with ASD are better than typically developed persons in differentiating between highly similar targets (26). In the auditory domain, individuals with ASD display increased levels of perfect pitch, and enhanced abilities to label isolated musical notes (27), to discriminate between two very similar pitches $(28,29)$, and to pick out changes in pitch in melodies more easily (30). With regard to multisensory processing, individuals with ASD are less susceptible than well-matched typically developing persons to the McGurk effect $(31,32)$ which occurs when the visual of a mouth or face formulating a sound $(e . g . / \mathrm{ba} /)$ is presented simultaneously with a different sound (e.g. /ga/). Typically developing persons, when presented with these discordant multisensory stimuli, frequently report hearing or seeing a third sound, /da/, which represents a perceptual midpoint between the two sounds. This suggests an integration of the multisensory input. Persons with ASD were less affected by the visual input and were more likely to report hearing the correct sound suggesting that the mechanisms behind integration of stimuli are different in ASD. Typically there is a bias towards visual information when audio-visual objects are combined $(33,34)$.

\section{CONCLUSIONS}

The unique and extreme reactions displayed by persons with ASD might seem to an observer to be idiosyncratic to a specific time or incident, however, the evidence from reports suggests that individuals with ASD may show a unique sensory profile. A disruption in the processing of basic sensory stimuli and the automatic integration of sensory information, which is considered a very low level process, will have an impact on the way a person experiences the world, learns language and interacts with both the physical and social environment, problems that are core to a diagnosis of autism spectrum disorders.

\section{ACKNOWLEDGEMENTS}

We would like to thank the Carnegie Trust for funding a research visit to Montreal to MS which enabled this paper to be written, and also for funding vacation scholarships to JB and LM which enabled their contribution.

\section{REFERENCES}

1. O'Neill M, Jones RS. Sensory-perceptual abnormalities in autism: a case for more research? Journal of autism and developmental disorders. 1997 Jun;27(3):283-93.

2. Rogers SJ, Ozonoff S. Annotation: what do we know about sensory dysfunction in autism? A critical review of the empirical evidence. Journal of child psychology and psychiatry, and allied disciplines. 2005 Dec;46(12):1255-68.

3. Shore SM. Beyond the wall: Personal experiences with Autism and Asperger Syndrome. Shawnee Mission, KA: Autism Asperger Publishing Co. 2001.

4. Attwood T. Asperger's syndrome: A guide for parents and professionals: Philadelphia: Jessica Kingsley. 1998.

5. Jones RSP, Quigney C, Huws JC. First hand accounts of sensory perceptual experience in autism: a qualitative analysis. Journal of Intellectual and Developmental Disability. 2003;28:112-21.

6. Grandin T. My experiences with visual thinking, sensory problems, and communication difficulties. Available online: http://wwwautismorg/temple/visualhtml.

7. Grandin T. Teaching tips from a recovered autistic. Focus on Autistic Behavior. 1988;3:8.

8. Williams D. Autism: An inside-out approach. London: Jessica Kingsley 1996.

9. Mukhopadhyay TR. The mind tree: a miraculous child breaks the silence of autism: Arcade Publishing 2003.

10. Dunn W, Westman K. The sensory profile: the performance of a national sample of children without disabilities. Am J Occup Ther. 1997 Jan;51(1):25-34.

11. Ermer J, Dunn W. The sensory profile: a discriminant analysis of children with and without disabilities. Am J Occup Ther. 1998 Apr;52(4):283-90.

12. Kientz MA, Dunn W. A comparison of the performance of children with and without autism on the Sensory Profile. Am J Occup Ther. 1997 Jul-Aug;51(7):530-7.

13. Rogers SJ, Hepburn S, Wehner E. Parent reports of sensory symptoms in toddlers with autism and those with other developmental disorders. Journal of autism and developmental disorders. 2003 Dec;33(6):631-42.

14. Watling RL, Deitz J, White O. Comparison of Sensory Profile scores of young children with and without autism spectrum disorders. Am J Occup Ther. 2001 Jul-Aug;55(4):416-23.

15. Dunn W. The Sensory profile Manual. San Antonio, Tx: The Psychology Corporation 1999.

16. Baranek GT, David FJ, Poe MD, Stone WL, Watson LR. Sensory Experiences Questionnaire: discriminating sensory features in young children with autism, developmental delays, and typical development. Journal of child psychology and psychiatry, and allied disciplines. 2006 Jun;47(6):591-601.

17. Baranek GT. Efficacy of sensory and motor interventions for children with autism. Journal of autism and developmental disorders. 2002 Oct;32(5):397-422.

18. Dawson $\mathrm{G}$, Watling $\mathrm{R}$. Interventions to facilitate auditory, visual, and motor integration in autism: a review of the evidence. Journal of autism and developmental disorders. 2000 Oct;30(5):415-21. 
19. Tomchek SD, Dunn W. Sensory processing in children with and without autism: a comparative study using the short sensory profile. Am J Occup Ther. 2007 Mar-Apr;61(2):190-200.

20. Leekman RS, Libbv SJ, Wing L, Gould J, Taylor C. The diagnostic interview for social and communication disorders: Algorithms for ICD-10 childhood autism and Wing and Gould autistic spectrum disorder. Journal of Child Psychology and Psychiatry. 2002;43:327-42.

21. Leekman RS, Nieto C, Libbv SJ, Wing L, Gould J. Describing the sensory abnormalities of children and adults with autism. Journal of autism and developmental disorders. 2007;37:894910 .

22. Wing L, Leekam SR, Libby SJ, Gould J, Larcombe M. The Diagnostic Interview for Social and Communication Disorders: background, inter-rater reliability and clinical use. Journal of child psychology and psychiatry, and allied disciplines. 2002 Mar;43(3):307-25

23. Mottron L, Burack J. Enhanced perceptual functioning in the development of autism. In: J. A. Burack TC, N. Yirmiya, and P. R. Zelazo ed. The development of autism: Perspectives from theory and research: Mahwah, NJ: Lawrence Erlbaum Associates. 2001:131-48.

24. Mottron L, Dawson M, Soulieres I, Hubert B, Burack J. Enhanced perceptual functioning in autism: an update, and eight principles of autistic perception. Journal of autism and developmental disorders. 2006 Jan;36(1):27-43.

25. Shah A, Frith U. An islet of ability in autistic children: a research note. Journal of child psychology and psychiatry, and allied disciplines. 1983 Oct;24(4):613-20.

26. Plaisted K, O'Riordan M, Baron-Cohen S. Enhanced discrimination of novel, highly similar stimuli by adults with autism during a perceptual learning task. Journal of child psychology and psychiatry, and allied disciplines. 1998 Jul;39(5):765-75.

27. Heaton P, Hermelin B, Pring L. Autism and pitch processing: a precursor for savant musical ability? . Music Perception. 1998;15:291-305.

28. Bonnel A, Mottron L, Peretz I, Trudel M, Gallun E, Bonnel AM. Enhanced pitch sensitivity in individuals with autism: a signal detection analysis. Journal of cognitive neuroscience. 2003 Feb 15;15(2):226-35.

29. O'Riordan M, Passetti F. Discrimination in autism within different sensory modalities. Journal of autism and developmental disorders. 2006 Jul;36(5):665-75.

30. Foxton JM, Stewart ME, Barnard L, Rodgers J, Young AH, O'Brien $\mathrm{G}$, et al. Absence of auditory 'global interference' in autism. Brain. 2003 Dec;126(Pt 12):2703-9.

31. DeGelder B, Vroomen J, van der Heide L. Face recognition and lip-reading in autism. European Journal of Cognitive Psychology. 1991;3:69-86.

32. Smith EG, Bennetto L. Audiovisual speech integration and lipreading in autism. Journal of child psychology and psychiatry, and allied disciplines. 2007 Aug;48(8):813-21.

33. Bertelson P. Ventriloquism: A case of crossmodal perceptual grouping. . In: G.Aschersleben TB, \& J. Musseler, ed. Cognitive contributions to the perception of spatial and temporal events. Amsterdam: Elsevier Science 1999:347-62.

34. Welch RB, Warren DH. Intersensory interactions. In: K. R. Boff LK, \& J. P. Thomas, ed. Handbook of perception and performance: Sensory processes and perception. New York, NY: John Wiley and Sons 1986:25-36. 